\title{
MECHANICAL PERFORMANCE OF THROUGH-THICKNESS TUFTED SANDWICH STRUCTURES
}

\author{
Anamaría Henao $^{1}$, Marco Carrera $^{1}$, Antonio Miravete ${ }^{2}$, Luis Castejón ${ }^{1}$ \\ ${ }^{1}$ Department of Mechanical Engineering \\ University of Zaragoza \\ C/ Maria de Luna 3, 50018 Zaragoza, Spain \\ e-mail: ahenao@unizar.es \\ ${ }^{2}$ Institute of Materials Science of Aragón \\ C/ Maria de Luna 3, 50018 Zaragoza, Spain
}

\begin{abstract}
This paper presents a study about the influence of through-thickness tufted fibres on compression and bending properties of sandwich structures. The tufting process aims to avoid the delamination between the skin and core in order to improve the performance of sandwich structures, increase the interlaminar strength and damage tolerance of sandwich structures.

To evaluate the effect of tufting in sandwich structures, an experimental study was developed which included edgewise compression and 3-P bending tests of tufted and nontufted sandwich panels made of carbon/epoxy and E-glass/epoxy face sheets, PVC and PUR foam cores and E-glass and aramid through-thickness fibres with different tufting densities.
\end{abstract}

Conclusions about the efficiency of the insertion of through-thickness fibres on compression and bending properties are drawn.

Key words: Sandwich Structures, Tufting, Edgewise Compression Tests, bending tests.

\section{INTRODUCTION}

Sandwich structures have been used in many types of application because of their lightweight, high bending stiffness and good behaviour under fatigue. However, the stability of this kind of structures is characterized by their buckling failure. This behaviour can be explained by several mechanisms such as fibre breaking, debonding of the face-skin from the core and the delamination in the faces. These mechanisms reduce the capacity to bear load leading to premature failure [1].

The presence of debonding is a mayor problem in sandwich construction, because they are susceptible to buckling under edge-wise compression, and the debonded region can propagate and can lead a failure of core and face-sheet. Debonding is also a key issue in bending applications. The main cause of debonding is that there are different mechanical properties across the interface between face and core. Thus, it is essential enhance the interfacial bond by the insertion of fibre through-the thickness using a tufting process [1]. 
The tufting process is a new technique, which consists of the insertion of a threaded needle into dry fabrics or sandwich performs, and its removal from the piece along the same trajectory. The thread remains in the place by the friction between fibre and core, creating a 3D structure [2].

Among the publications concerning 3D sandwich structures may be cited the study carried out by Reis and Rizkalla [3] who summarized the findings of an experimental program to determine the various parameters believed to affect the material characteristics of these sandwich panels. The influence of the panel thickness, through-thickness fibre configuration and density, and other parameters on the tension, compression, flexure and shear behaviour of the panels were studied by Long et al. [4]. Sharma et al.[1] investigated the characteristics of the specimens with through-thickness stitches and the influence of strain rate on buckling. Stanley and Adams [5] explored the feasibility and potential benefits provided by the addition of though-the-thickness reinforcement to sandwich structures. Their results show significant increase in the flexural stiffness and strength, out-of-plane tensile strength, core shear strength, edgewise compression strength and compression after impact strength of stitched sandwich structures. Raju and Tomblin [6] investigated the energy abruption characteristics of sandwich panels with through-the -thickness stitches, under edgewise compression. XiTao [7] et al. quantified the effect of structural through-thickness reinforcement in foam core sandwich composite panels, an experimental study was carried out which included three-point bending tests, core shear tests, flatwise tensile and compression tests, as well as edgewise compression tests. Bannister et al. [8] conducted flatwise compression, edgewise compression, climbing drum peel and flexure tests on 3D weaved sandwich structures.

These references are related to weaved and stitched through-thickness reinforcement schemes, whose typical loops and knots significantly deteriorate the 3D fibre architecture. Differently, the present work deals with a clean, single-need technique that allows the manufacturing of complex 3D shaped sandwich panels by means of tufting heads with minimum effect on the fibre network.

The aim of this investigation is study the mechanical performance of tufting addition in sandwich structures under edgewise compression and bending loads, evaluating different tufting densities, two different face materials, such as carbon and glass fibre and two core materials, PVC and PUR.

\section{THE TUFTING PROCESS}

The tufting technology is based on conventional stitching process, where a dual-threading system makes the seam by forming loops and knots, this kind of seam significantly deteriorate the mechanical performance of the 3D fibre architecture. The novel aspect involved in the tufting process is that it uses a single needle that introduces a thread into the structure without tension. This results in a reduction of the stitching effect on the in-plane properties. After injection of the resin, the structure is consolidated in one piece with higher properties that one without reinforcement through the thickness [9]. 
During the tufting process a thread is introduced into a pre-form by one needle under an angle of $90^{\circ}$ or $45^{\circ}$. When the needle goes out of the piece the thread is retained by friction between the fabrics or foam with the thread, forming a loop [10]. Figure 1 shows the difference between the complex procedure of stitching (left) and the clean and simple tufting scheme (left). Essentially tufting is equivalent to Z-pinning, but used to reinforce dry fabrics prior to resin injection using Liquid Composite Moulding techniques.

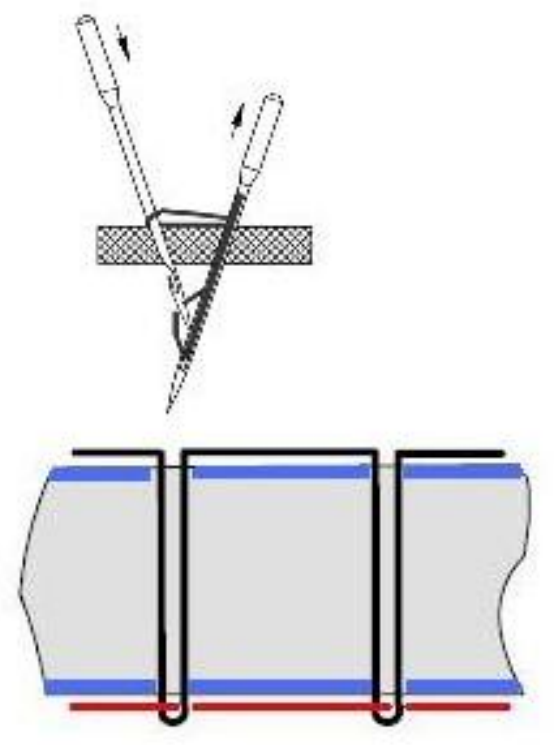

STITCHING

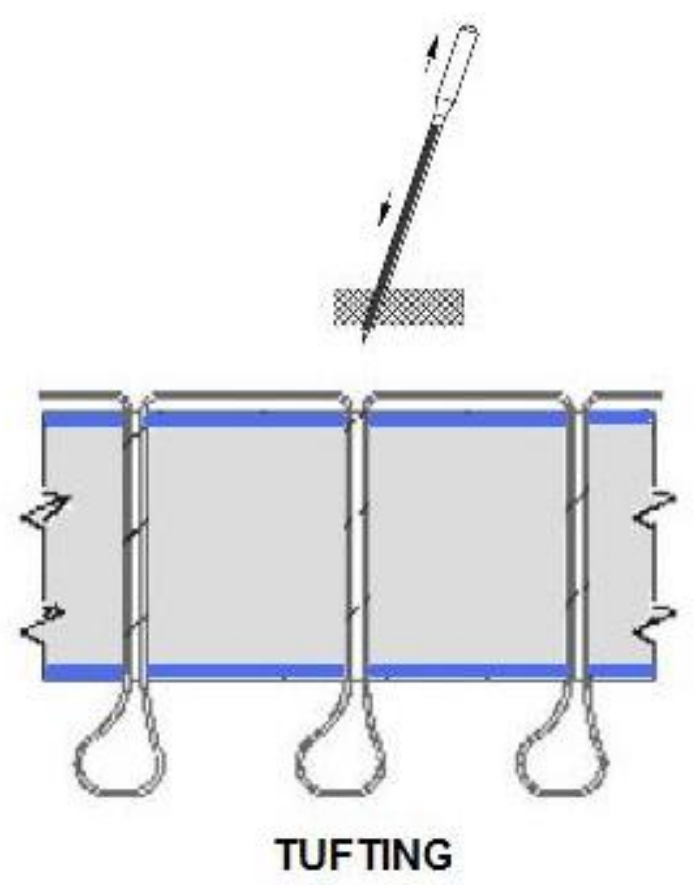

TUFTING

Figure 1. Schemes of stitching (left) and tufting (left) applied to sandwich panels

This process has been applied by means of a tufting head (KSL KL 150), controlled by a Fanuc 6-axis robot, both are shown in Figure 2. The maximum thickness of the pre-form is 40 $\mathrm{mm}$, and it is possible to control variables such as stitch length, insertion angle and the length of the loop.

In the tufting process, a needle of $2 \mathrm{~mm}$ diameter is used to provide enough robustness to develop repeated applications. The dry perform is formed by two faces made out of fabrics and the core made out of a foam. Then, they are assembled into a dry sandwich structure by tufting, the parameters being previously set. 


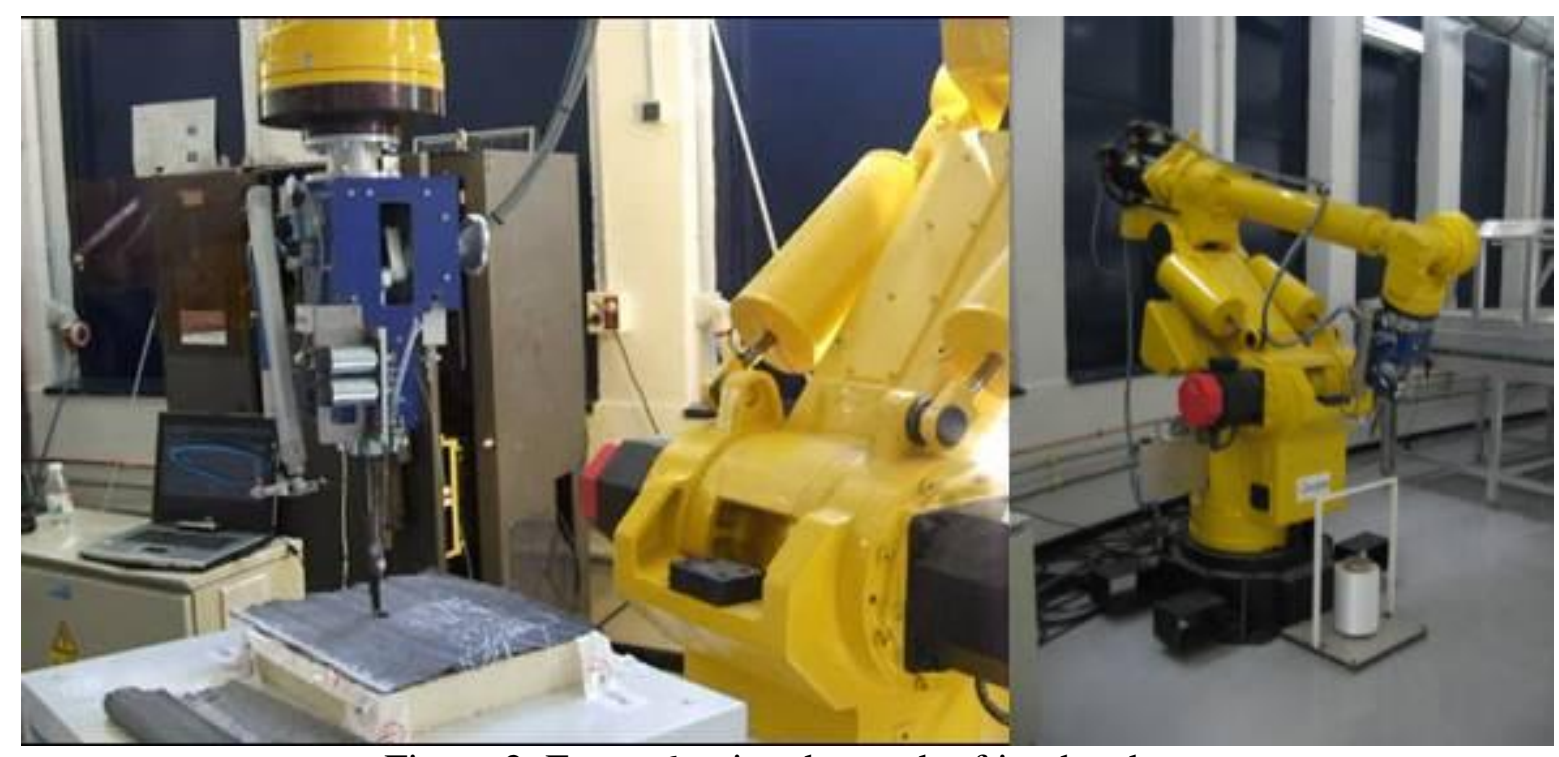

Figure 2. Fanuc 6-axis robot and tufting head

The impregnation of the sandwich structure is made by means of the Vacuum Assisted Resin Transfer Moulding (VARTM) process.

\section{MATERIALS}

Two material systems have been used for the sandwich faces: carbon/epoxy and Eglass/epoxy. In terms of core materials, $80 \mathrm{~kg} / \mathrm{m}^{3} \mathrm{PVC}$ and $40 \mathrm{~kg} / \mathrm{m}^{3}$ polyurethane foams have been utilised. Both, tufted and non-tufted sandwich panels have been studied in compression.

Glass and carbon fibre face, PUR cored sandwich panels were used for the bending tests. Both types of sandwich panels were fabricated with no tufting and tufted with aramid yarns.

The E-glass fabric used for the faces was $800 \mathrm{gr} / \mathrm{m}^{2}$ [0/90] woven fabric. The carbon fibre was also a woven fabric with a density of $980 \mathrm{~g} / \mathrm{m}^{2}$ and a layup of [0/90] as well. The properties of these materials are shown in Table 1.

Table 2 summarises the attributes of the E-glass thread used to make tufting in PVC structures. This fibre has been used in these types of applications for some time.

The properties of the aramid fibre used for the tufting of sandwich panels for the bending tests are shown in the Table 3.

\section{EXPERIMENTAL PROGRAM}

Edgewise compression and $3 \mathrm{P}$ bending tests were performed to determine the effects of tufted reinforcements on the mechanical properties of sandwich structures. ASTM C 364/C 364M - 07 "Standard test method for edgewise compressive strength of sandwich constructions" and ASTM C393/C 393M - 06 "Standard test method for flexural properties of sandwich constructions" were followed. This section discusses the procedures followed during the tests as well as the test results. In all the cases, five specimens were tested per 
every type of sandwich panel, all the results presented in this paper are obtained from valid tests, the specimens that failed at the edges of the samples were ruled out.

\subsection{Edgewise Compression Tests}

The edgewise compressive test of 3D sandwich structures gives a basis for judging the load-carrying capacity, in order to determine if the tufting addition improves the performance of this type of constructions with different tufting densities [11].

An Instron 8032 test machine was used to run the present tests. The specimen dimensions were $140 \mathrm{~mm}$ length and $70 \mathrm{~mm}$ width. The load was applied with a constant rate of 1 $\mathrm{mm} / \mathrm{min}$.

Two types of sandwich structures with PVC core were tested under edgewise compression: carbon fibre and E-glass fibre face sandwich panels. Both structures were tufted with different densities, changing the spacing of the tufted reinforcements.

\subsubsection{Carbon fibre faces/ PVC core sandwich panels}

Table 4 represents dimensions and numerical results for carbon fibres faces and PVC core coupons (CF-PVC).

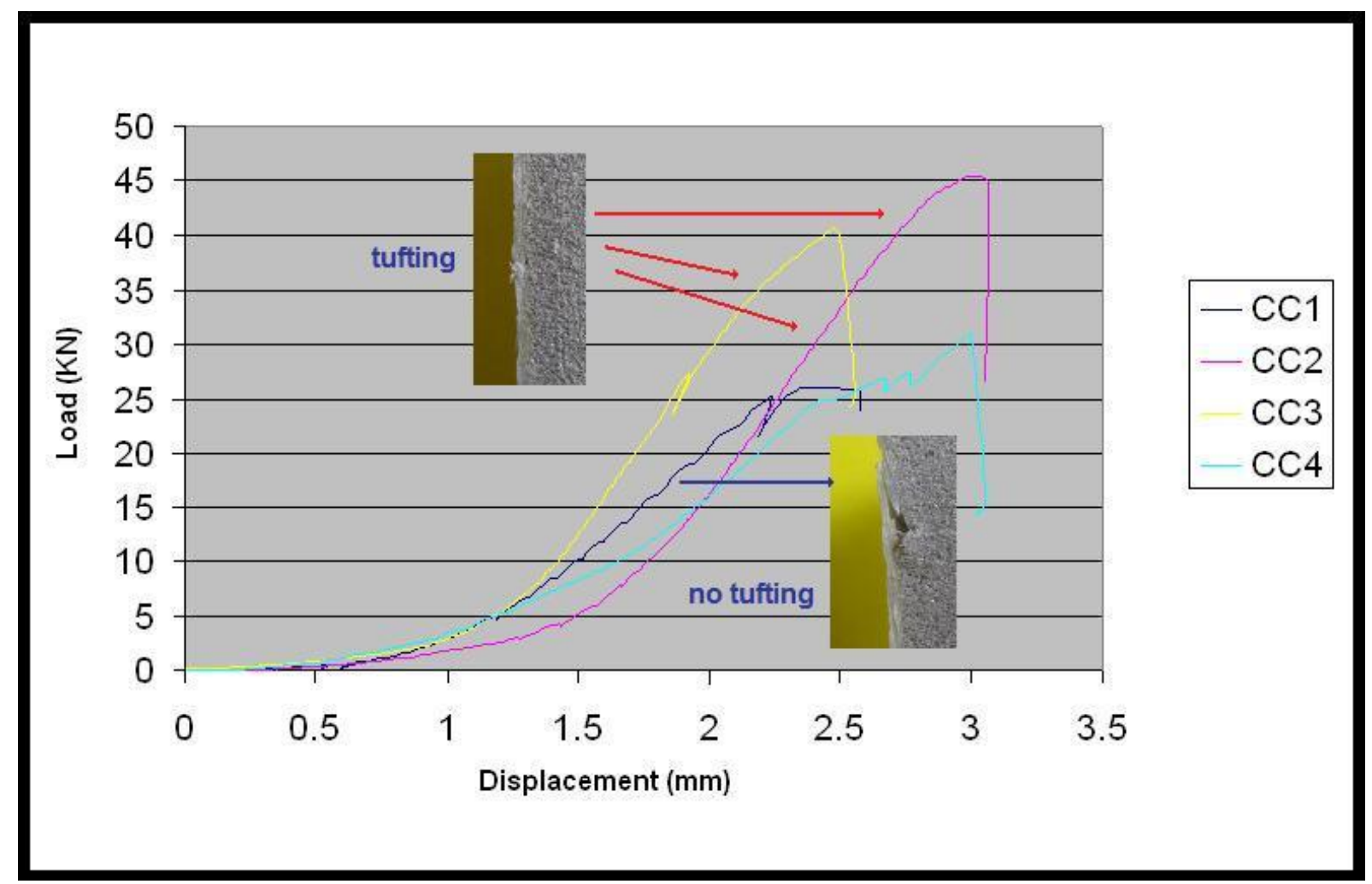

Figure 3. Load/displacement curves of tufted and non-tufted carbon fibre/PVC core sandwich panels and failure mechanisms under edgewise compression 
Results from edgewise compression tests are presented in table 6 for sandwich structures with carbon fibre faces.

Figure 3 shows the load versus crosshead displacement plot of specimens with different tufting densities and carbon fibre face sandwich panels. For all specimens, the load increases until the maximum failure load, after this point the load decreases abruptly. Examination of the failed specimens showed that the tufted sandwich panels failed -at higher load than the non-tufted coupons- by inward buckling of the facesheets (Figure 3). Figure 4 shows a detail of two failures in a tufted coupon. Non-tufted coupons failed as a result of the facesheets delaminating from the foam core and buckling outward.

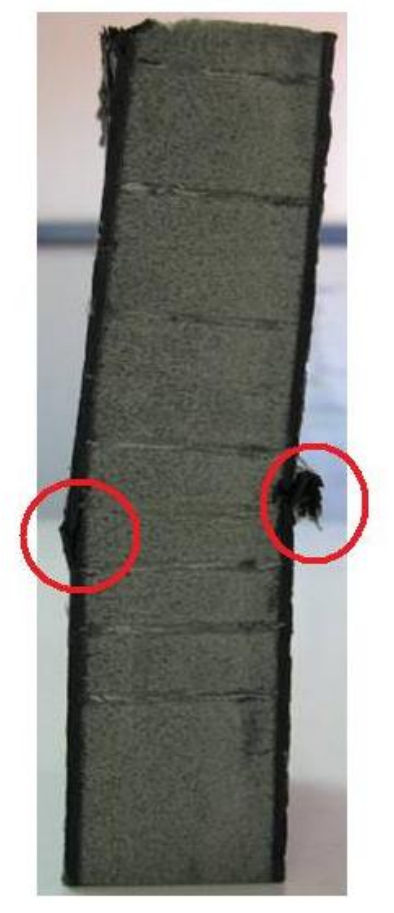

Figure 4. Detail of two inward buckling failures of a carbon fibre tufted sandwich panel

The increase of the edgewise compression strength was $25.23 \%, 13.22 \%$ and $7.54 \%$, for tufting spacing values of $5 \mathrm{~mm}, 10 \mathrm{~mm}$ and $15 \mathrm{~mm}$ respectively. The area under the load versus displacement curve, which is the energy absorption, increases as well $104.01 \%$, $52.48 \%$ and $25.87 \%$, for spacing values of $5 \mathrm{~mm}, 10 \mathrm{~mm}$ and $15 \mathrm{~mm}$, respectively. Therefore, in terms of edgewise compression strength, tufted sandwich panels exhibit a lightly higher increase of the edgewise compression strength that non-tufted coupons, the most efficient spacing being $5 \mathrm{~mm}$.

4.1.2. Glass fibre face/PVC core sandwich panels 
The second sandwich structure that was tested in compression is formed by glass fibre faces and PVC core (GF-PVC). Some coupons were tufted with glass fibre threads with different spacing distances.

Table 5 represents dimensions and numerical results for glass fibres faces and PVC core coupons (CF-PVC).

Figure 5 shows the load versus crosshead displacement plot of some specimens with different tufting densities and glass fibre face sandwich. An inspection of the failed specimens showed that the sandwich panels with glass fibre faces failed by inward buckling of the facesheets. Non-tufted coupons failed as a result of the facesheets delaminating from the foam core and buckling outward, similarly to the carbon fibre panels. Therefore, with both, carbon and glass fibre faces, there is a change of failure mechanism from skin-core debonding to inward skin bucking when including tufted fibres.

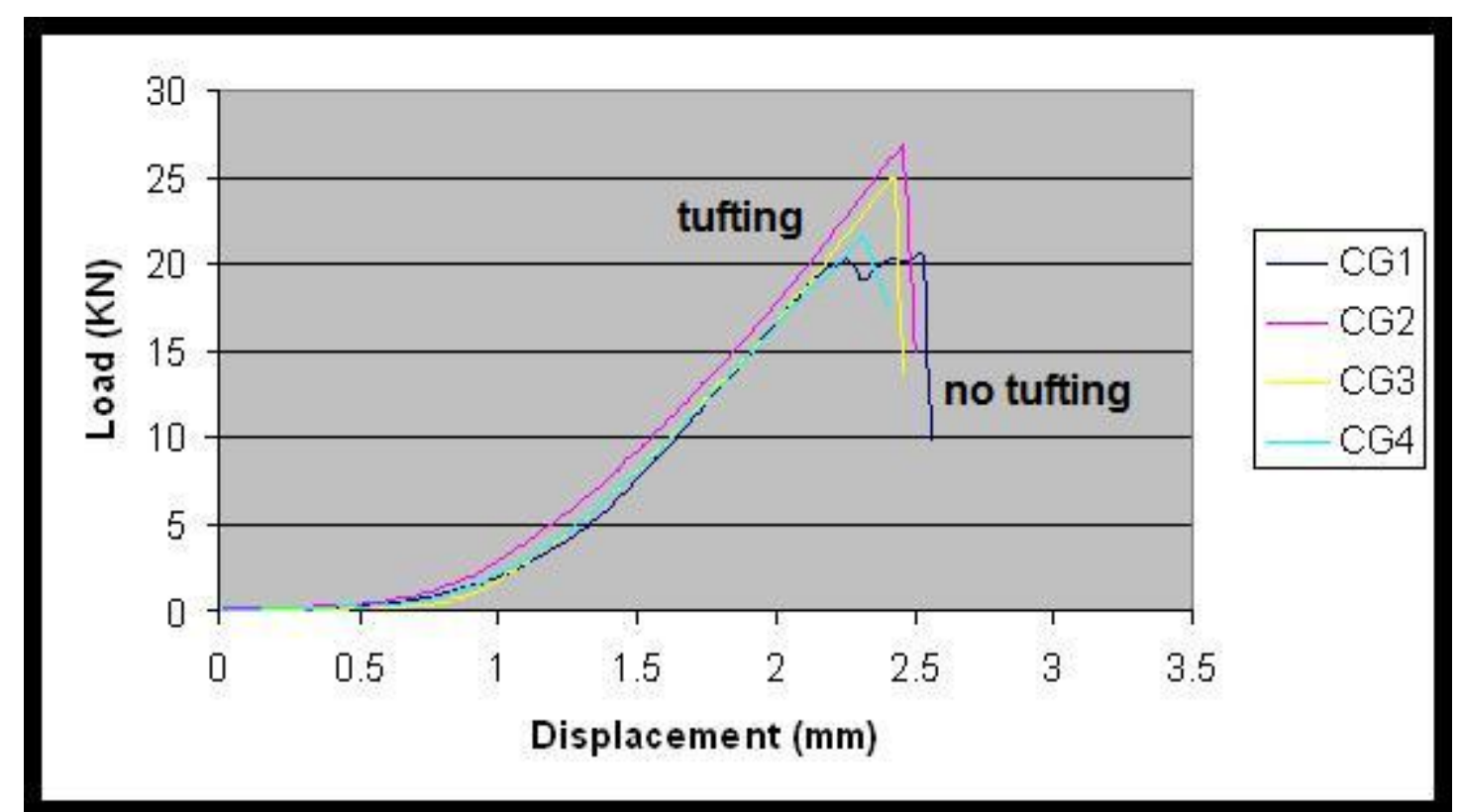

Figure 5. Load/displacement curves of tufted and non-tufted E-glass fibre/PVC core sandwich panels under edgewise compression

The evaluation of glass fibre face sandwich panels reflects that the edgewise compression strength increases $20.32 \%, 3.16 \%$ and $1.10 \%$, and the energy absorption improve $111.11 \%$, $12.41 \%$ and $7.04 \%$, for $5 \mathrm{~mm}, 10 \mathrm{~mm}$ and $15 \mathrm{~mm}$ of spacing between consecutive tufted fibres, respectively. As occurred with carbon fibre faces, glass fibre sandwich panels present a small increase of the edgewise compression strength that non-tufted coupons, the most efficient spacing being $5 \mathrm{~mm}$. The increase of the glass fibre sandwich panels is lower than the carbon fibre.

\subsection{Bending tests}


3P bending tests were conducted according to ASTM C393/C 393M - 06 "Standard Test Method for flexural properties of sandwich constructions". This test allows the determination of the facing bending strength [12].

The dimensions of the specimens were selected according to the recommendations of the standard. The specimens had rectangular cross section. The span was $300 \mathrm{~mm}$, the total length of the coupons was $350 \mathrm{~mm}$, width was $90 \mathrm{~mm}$, and thickness was about $32 \mathrm{~mm}$.

The bending tests were conducted over sandwich panels with and without tufting, as well. The tufted panel, Acrosoma ${ }^{\circledR}$, was provided by Composite Trailer. The tufting was carried out by means of aramid yarns with a spacing of $12.5 \mathrm{~mm}$. These coupons were fabricated with PUR foam core and two different face materials, carbon and glass fibre with epoxy resin.

A mid span loading was conducted using an electromechanical testing machine at a constant crosshead displacement of $4 \mathrm{~mm} / \mathrm{min}$. Load and displacements were recorded during the test.

\subsubsection{Carbon fibre face/PUR core sandwich panels}

Table 6 represents dimensions and numerical results for carbon fibre faces and PUR core coupons (CF-PUR). These results show that the failure load increases in the tufted specimens over $60 \%$ in comparison with the non tufted ones.

Figure 6 displays the load versus crosshead displacement plot of specimens with and without tufting of carbon fibre face sandwich. For all specimens, the load increases until the maximum failure load, after this point the load decreases progressively. Table 6 shows that the face bending strength increased $56.79 \%$ with the insertion of tufting threads. 


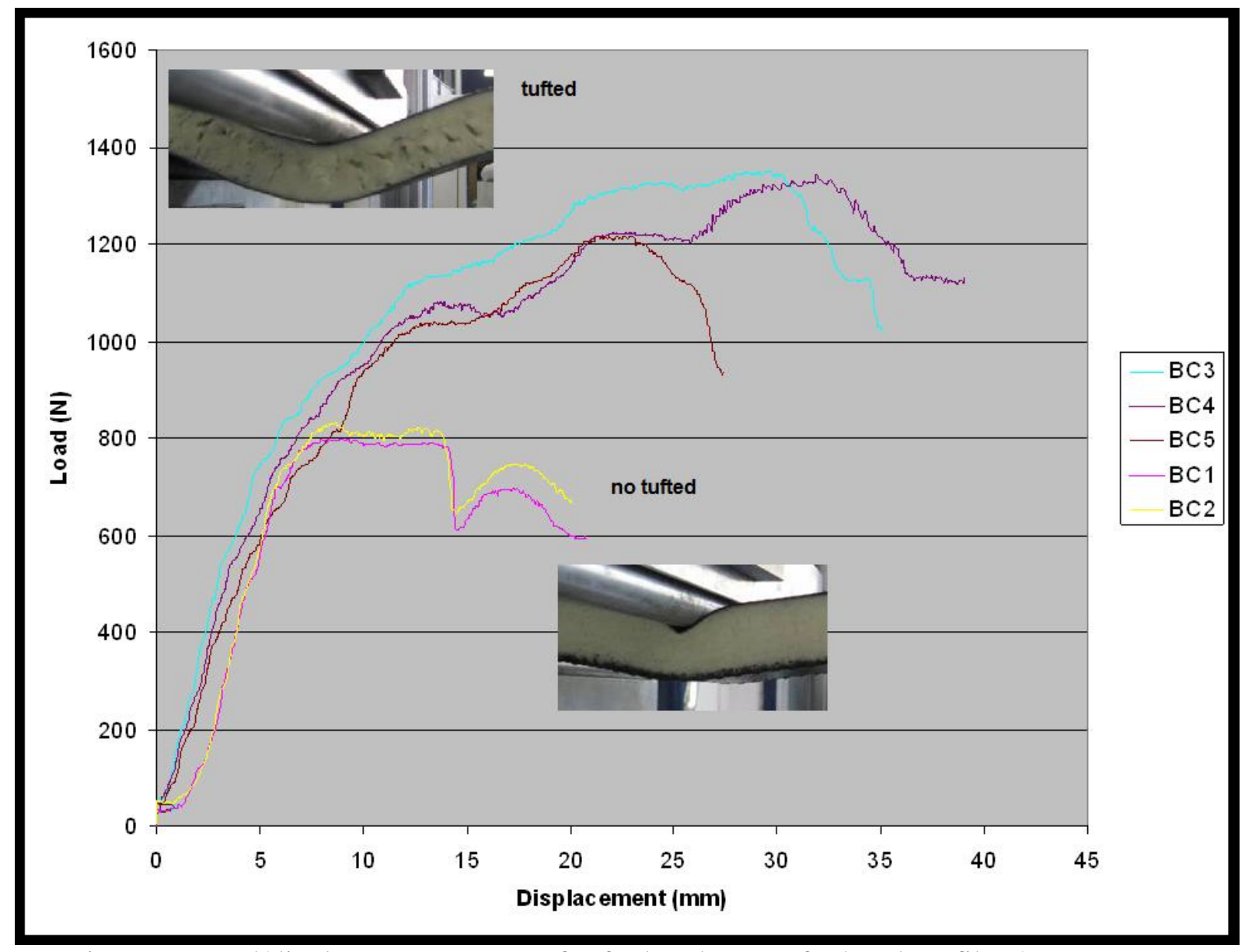

Figure 6. Load/displacement curves of tufted and non-tufted carbon fibre/PUR core sandwich panels and failure mechanisms under $3 \mathrm{P}$ bending

The failure of the specimens without tufted fibres is mainly indentation, which is a dominant mode of failure in cases of highly localized external loads, such as point or line loads. The failure process consists of local yielding and deformation of the core material under the highly loaded area followed by significant local deformation of the loaded facing into the core. This results in a complex elastic-plastic multiaxial state of stress in the vicinity of localized loads. (Figure 6). On the other hand, the failure in the sandwich with tufting is core failure (Figure 6). Due to the strong bridging between skins through the tufted aramid fibres, top skin and core deforms together until the core deformation reachs the critical one and the core fails by shear.

\subsubsection{Glass fibre face /PUR foam core sandwich panels}

Table 7 represents dimensions and numerical results for glass fibre faces and PUR core coupons (GF-PUR). These test results show a $113.47 \%$ increase of the face bending strength with the addition of tufting. Figure 7 shows the test results. 


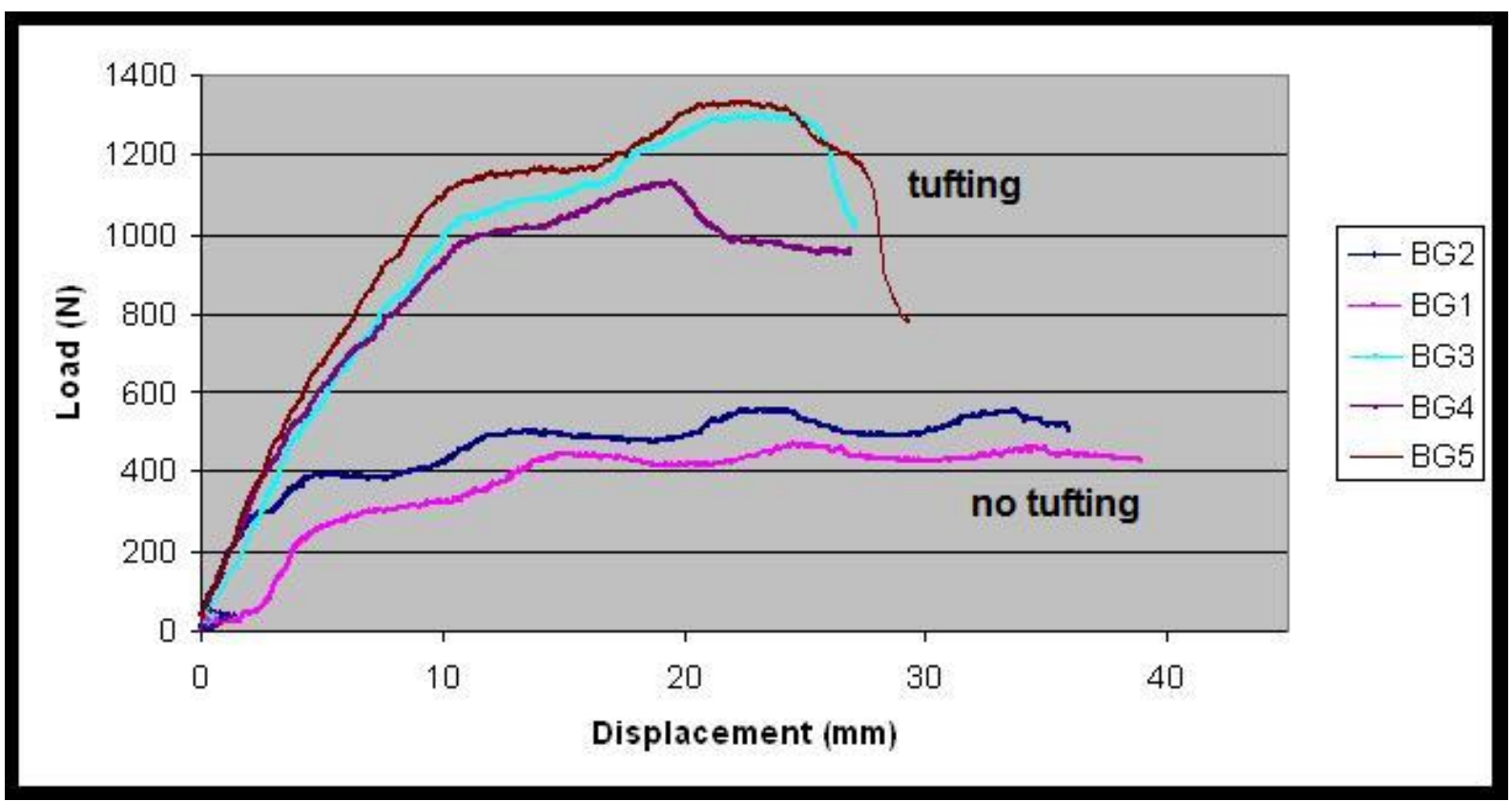

Figure 7. Load/displacement curves of tufted and non-tufted E-glass fibre/PUR core sandwich panels and failure mechanisms under 3P bending

As occurred in the carbon fibre panel, failure of the specimens without tufted fibres is mainly indentation, while the failure in the sandwich with tufting is core failure. Therefore, a change of failure mechanism is reported for both carbon and glass fibre sandwich panels.

\section{CONCLUSIONS}

Edgewise compression and bending test were carried out over carbon and glad skin, PVC and PUR foam core sandwich panels to explore the performance of sandwich structure with and without tufted through-thickness reinforcements.

Sandwich panels were tufted in a dry form, after this step, a VARTM process was applied. The sandwich panels without tufted through-thickness reinforcements were produced by the same system.

Compression test results showed a modest increase in the edgewise compression strength when tufted through-thickness reinforcements were added: in the case of carbon/epoxy face/ PVC core sandwich panels, the improvement was of $25.23 \%$ for a tufting spacing of $5 \mathrm{~mm}$. Although the improvement reported in the E-glass/epoxy face/PVC core sandwich panels was not as high as in carbon faces, their edgewise compression strength was increased by $20.32 \%$ with the insertion of tufted reinforcements for the same distance. $5 \mathrm{~mm}$ spacing becomes more efficient that 10 or $15 \mathrm{~mm}$. Energy absorption increased $104.01 \%$ and $111.11 \%$ for carbon and glass sandwich panels, respectively when adding tufted reinforcements.

The 3P bending test results showed significant strength increase when tufted reinforcements were applied. For the carbon fibre face sandwich panels, the increase of the 
face bending strength is $56.79 \%$. For the case of glass fibre faces the increase is even higher, $113.47 \%$.

The comparison between the results obtained during these tests on tufting specimens, and the data found in the bibliography about stitching coupons (5) shows that the tufting process improves 57\% respect to stitching in edgewise compression, although in bending test results, there is not any appreciable improvement between both kind of process.

The main conclusion is that tufted sandwich panels are an efficient configuration that enhance their mechanical performance by means of through-thickness reinforcements, especially under bending stresses. Edgewise compression strength also increases when adding tufting, though the tufting efficiency is lower than in bending.

\section{REFERENCES}

1. Sharma S.C., Krishna M. and Narasimha H. N. Buckling Response of Stitched Polyurethane Foam Composite Sandwich Structures. Journal of Reinforced Plastics and Composites, 2004:; 23; 1267

2. Dell Anno G., Cartié D.D., Partridge I.k., Rezai A. Exploring mechanical property balance in tufted carbon fabric/epoxy composites. Composites: Part A 38 ,2007: 23662373

3. Reis E.M., Rizkalla S.H.. Material characteristics of 3-D FRP sandwich panels. Construction and Building Materials, 2007.

4. Tong L., Mouritz A.P. and Bannister M.K. 3D fibre Reinforced polymer composites. Elsevier Science ltd. Oxford, 2002.

5. Stanley L.E. and Adams D.O. Development and evaluation of stitched sandwich panels. NASA/CR-2001-211025.

6. Raju K.S. and Tomblin J.S.. Energy absorption characteristics of stitched composite sandwich panels. Journal of Composite Materials 1999; 33; 712

7. XiTao Z., JianFeng Z., Fan Y., YaNan C., Ye L. Experimental and Analytical Study on the Mechanical Behavior of Stitched Sandwich Composite Panel with a Foam Core. Advanced Materials Research Vols. 33-37, 2008: 477-482

8. Bannister M.K., Braema R., Crothers P.J. The mechanical performance of 3D woven sandwich composites. Composite Structures 47, 1999: 687-690

9. Sickinger C., Hermann A.. Structural stitching as a method to design High-Performance Composite in future

10. Cartié D.D.R., Dell Anno G., Poulin E., Partidge I.K.. 3D reinforcement of stiffener-toskin T-Joints by Z-pinning and tufting. Engineering Fracture Mechanics 73, 2006: 25322540.

11. ASTM C 364/C 364M - 07 "Standard test method for edgewise compressive strength of sandwich constructions" American Society for Testing and Materials Annual Book for ASTM standards, 2007. 
12. ASTM C393/C 393M - 06 "Standard test method for flexural properties of sandwich constructions" American Society for Testing and Mateials Annual Book for ASTM standards, 2006.

13. Fleck N.A. And Sridhar I. End compression of sandwich columns. Composite: Part A 33, 2002: 353-359.

14. Mamalis A.G., Manolakos D.E., Ioannidis M.B., Papapostolou D.P. On the crushing response of composite sandwich panels subjected to edgewise compression: experimental. Composite Structures 71, 2005: 246-257.

15. Camarda C.J. Test of graphite/polyimide sandwich panels in uniaxial edgewise compression. Langley Rearsch Center. Hampton, Virginia.1980.

16. Gdoutos E.E., Daniel I.M., Wang K.-A.. Compression facing wrinkling of composite sandwich structures. Mechanics of Materials 35, 2003: 511-522

17. Ley R.P., Lin W. and Mbanefo U. Facesheet wrinkling in sandwich structures. Nasa/CR1999-208994.

18. May-Pat A. and Avilés F. Análisis numérico de fractura interfacial en columnas sandwich sometidas a compression axial. Ingenieria 11-3,2007: 21-32

19. Sleight D.W. and Wang J.T. Buckling analysis of debonded sandwich panel under compression. Nasa Technical memorandum 4701.

20. Hadi B.K. Wrinkling of sandwich column: comparison between finite element analysis and analytical solutions. Composite Structures 53 ,2001. 477-482.

21. Corigliano A., Rizzi E., Papa E.. Experimental characterization and numerical simulations of a syntactic-foam/glass-fibre composite sandwich. Composites Science and Technology 60, 2000: 2169-2180.

22. Gdoutos E.E., Daniel I.M. Failure modes of composite sandwich beams. Theoretical Applied Mechanics, Vol. 35, No.1-3, Belgrade 2008: 105-118.

23. Mouritz A.P., Leong K.H. and Herszberg I.. A review of the effect of stitching on the inplane mechanical properties of fibre-reinforced polymer composites. Composites Part A 28A, 1997: 979-991

24. Russo A., Zuccarello B.. Experimental and numerical evaluation of the mechanical behavior of GFRP sandwich panels. Composite Structures 81, 2007: 575-586.

25. W., N. Petrinic, A. Hornig, A. Langkamp, M. Gude, J. Wiegand. Delamination behaviour of 3d-textile reinforced composites - experimental and numerical approaches. Dresden, Germany.

26. Lascoup B., Aboura Z., Khellil K., Benzeggagh M.. On the mechanical effect of stitch addition in sandwich panel. Composites Science and Technology 66, 2006: 1385-1398.

27. I.M.Daniel, O. Ishai. Engineering mechanics of composite materials. Second edition. Oxford University Press. New York, 2006. 


\section{FIGURE CAPTIONS}

Figure 1. Schemes of stitching (left) and tufting (left) applied to sandwich panels

Figure 2. Fanuc 6-axis robot and tufting head

Figure 3. Load/displacement curves of tufted and non-tufted carbon fibre/PVC core sandwich panels and failure mechanisms under edgewise compression

Figure 4. Detail of two inward buckling failures of a carbon fibre tufted sandwich panel

Figure 5. Load/displacement curves of tufted and non-tufted E-glass fibre/PVC core sandwich panels under edgewise compression

Figure 6. Load/displacement curves of tufted and non-tufted carbon fibre/PUR core sandwich panels and failure mechanisms under $3 \mathrm{P}$ bending

Figure 7. Load/displacement curves of tufted and non-tufted E-glass fibre/PUR core sandwich panels and failure mechanisms under $3 \mathrm{P}$ bending 


\section{TABLES}

Table 1. Laminate faces properties

\begin{tabular}{|l|c|c|c|c|c|}
\hline \multirow{2}{*}{\multicolumn{1}{c}{ Face material system }} & \multicolumn{5}{|c|}{ Properties } \\
\cline { 2 - 6 } & $\mathrm{Vf}$ & $\begin{array}{c}\text { Aerial weight } \\
\left(\mathrm{g} / \mathrm{m}^{2}\right)\end{array}$ & Layup & $\begin{array}{c}\text { Ply thickness } \\
(\mathrm{mm})\end{array}$ & $\begin{array}{c}\text { Face thickness } \\
(\mathrm{mm})\end{array}$ \\
\hline Carbon fibre- (compression) & 0.55 & 980 & {$[0 / 90]_{2}$} & 0.98 & 1.97 \\
\hline Glass fibre- (compression) & 0.55 & 800 & {$[0 / 90]_{2}$} & 0.56 & 1.12 \\
\hline Carbon fibre-(bending) & 0.55 & 800 & {$[0 / 90]$} & 0.80 & 0.80 \\
\hline Glass fibre- (bending) & 0.55 & 350 & {$[0 / 90]$} & 0.24 & 0.24 \\
\hline
\end{tabular}

Table 2. Tufted glass fibre thread EC9 6X3 S260 properties

\begin{tabular}{|c|c|c|c|}
\hline $\begin{array}{c}\text { Specific weight } \\
(\mathrm{g} / \mathrm{km})\end{array}$ & $\begin{array}{c}\text { Filament } \\
\text { diameter }(\mu \mathrm{m})\end{array}$ & $\begin{array}{c}\text { Max load } \\
(\mathrm{N})\end{array}$ & Filament count \\
\hline 204 & 9 & 93 & 204 \\
\hline
\end{tabular}

Table 3. Tufted aramid fibre properties

\begin{tabular}{|c|c|c|c|}
\hline $\begin{array}{c}\text { Density } \\
\left(\mathrm{Kg} / \mathrm{m}^{3}\right)\end{array}$ & $\begin{array}{c}\text { Tensile } \\
\text { Strengh } \\
(\mathrm{MPa})\end{array}$ & $\begin{array}{c}\text { Tensile } \\
\text { Modulus } \\
(\mathrm{GPa})\end{array}$ & $\begin{array}{c}\text { Poisson } \\
\text { coeficcient }\end{array}$ \\
\hline 1450 & 3800 & 131 & 0.33 \\
\hline
\end{tabular}

Table 4. CF-PVC compression specimen dimensions and results

\begin{tabular}{|c|c|c|c|c|c|c|c|c|c|c|c|}
\hline \# & Faces & Core & $\begin{array}{c}\text { Tufting } \\
\text { spacing } \\
(\mathrm{mm})\end{array}$ & $\begin{array}{l}\text { Width } \\
(\mathrm{mm})\end{array}$ & $\begin{array}{c}\text { Length } \\
(\mathrm{mm})\end{array}$ & $\begin{array}{l}\text { Total } \\
\text { Thickness } \\
(\mathrm{mm})\end{array}$ & $\begin{array}{l}\text { Average } \\
\text { Load } \\
(\mathrm{KN})\end{array}$ & $\begin{array}{l}\text { Average } \\
\text { Energy } \\
\text { absorbed } \\
(\mathrm{N}-\mathrm{mm})\end{array}$ & $\begin{array}{l}\text { Average } \\
\text { Edgewise } \\
\text { facing } \\
\text { compression } \\
\text { stress (MPa) }\end{array}$ & $\begin{array}{c}\text { C.V. } \\
\%\end{array}$ & $\begin{array}{l}\text { Number } \\
\text { of } \\
\text { coupons }\end{array}$ \\
\hline CC1 & \multirow{4}{*}{ CF } & \multirow{4}{*}{ PVC } & - & 69.63 & 140 & 34 & 25.88 & 22.925 & 91.59 & 2.58 & 2 \\
\hline CC2 & & & 5 & 70.16 & 140.1 & 35.33 & 43.2 & 46.99 & 114.7 & 11.25 & 3 \\
\hline CC3 & & & 10 & 70 & 140.3 & 35.05 & 36.91 & 34.955 & 103.7 & 6.83 & 4 \\
\hline CC4 & & & 15 & 69.97 & 140.3 & 34.92 & 33.86 & 28.85 & 98.5 & 14.36 & 2 \\
\hline
\end{tabular}

Table 5. GF-PVC compression specimen dimensions and results

\begin{tabular}{|c|c|c|c|c|c|c|c|c|c|c|c|}
\hline$\#$ & Face & Core & $\begin{array}{l}\text { Tufting } \\
\text { spacing } \\
(\mathrm{mm})\end{array}$ & $\begin{array}{l}\text { Width } \\
(\mathrm{mm})\end{array}$ & $\begin{array}{l}\text { Length } \\
(\mathrm{mm})\end{array}$ & $\begin{array}{l}\text { Total } \\
\text { Thickness } \\
(\mathrm{mm})\end{array}$ & $\begin{array}{c}\text { Average } \\
\text { Load } \\
(\mathrm{KN})\end{array}$ & $\begin{array}{l}\text { Average } \\
\text { Energy } \\
\text { absorbed } \\
(\mathrm{N}-\mathrm{mm})\end{array}$ & $\begin{array}{l}\text { Average } \\
\text { Edgewise } \\
\text { facing } \\
\text { compression } \\
\text { stress (MPa) }\end{array}$ & $\begin{array}{c}\text { C.V. } \\
\%\end{array}$ & $\begin{array}{l}\text { Number } \\
\text { of } \\
\text { coupons }\end{array}$ \\
\hline CG1 & \multirow{4}{*}{ GF } & \multirow{4}{*}{ PVC } & - & 69.84 & 140 & 32.75 & 20.41 & 15.47 & 111.257 & 2.24 & 2 \\
\hline CG2 & & & 5 & 70.41 & 140 & 32.96 & 27.89 & 32.66 & 133.87 & 6.42 & 2 \\
\hline CG3 & & & 10 & 69.95 & 139.9 & 33.01 & 24.2 & 17.39 & 114.78 & 11.47 & 4 \\
\hline CG4 & & & 15 & 69.97 & 140.1 & 32.84 & 21.68 & 16.5675 & 112.49 & 8.89 & 4 \\
\hline
\end{tabular}


Anamaría Henao, Marco Carrera, Antonio Miravete, Luis Castejón.

Table 6. CF-PUR bending specimen dimensions and results

\begin{tabular}{|c|c|c|c|c|c|c|c|c|c|c|c|c|}
\hline \# & Face & Core & $\begin{array}{l}\text { Tufting } \\
\text { yarn }\end{array}$ & $\begin{array}{l}\text { Tuft } \\
\text { spacing } \\
(\mathrm{mm})\end{array}$ & $\begin{array}{l}\text { Width } \\
(\mathrm{mm})\end{array}$ & $\begin{array}{l}\text { Length } \\
(\mathrm{mm})\end{array}$ & $\begin{array}{l}\text { Total } \\
\text { Thick } \\
(\mathrm{mm})\end{array}$ & $\begin{array}{c}\text { Span } \\
(\mathrm{mm})\end{array}$ & $\begin{array}{l}\text { Failure } \\
\text { Load } \\
\text { (N) }\end{array}$ & $\begin{array}{c}\text { Facing } \\
\text { bending } \\
\text { stress } \\
\text { (Mpa) }\end{array}$ & $\begin{array}{c}\text { Average } \\
\text { facing } \\
\text { bending } \\
\text { stress } \\
\text { (Mpa) }\end{array}$ & C.V. \% \\
\hline $\mathrm{BC} 1$ & \multirow{5}{*}{ CF } & \multirow{5}{*}{ PUR } & \multirow{5}{*}{ Aramid } & \multirow[b]{2}{*}{ - } & 90.3 & 350 & 32.25 & \multirow{5}{*}{200} & 797.32 & 12.61 & \multirow{2}{*}{13.3361} & \multirow{2}{*}{7.705} \\
\hline $\mathrm{BC} 2$ & & & & & 91.2 & 350 & 32.09 & & 831.69 & 14.063 & & \\
\hline $\mathrm{BC3}$ & & & & \multirow{3}{*}{12.5} & 91 & 348 & 29.16 & & 1351.9 & 24.49 & \multirow{3}{*}{20.9087} & \multirow{3}{*}{14.92} \\
\hline $\mathrm{BC} 4$ & & & & & 90.9 & 347 & 29.68 & & 1343.4 & 19.458 & & \\
\hline BC5 & & & & & 90.6 & 348 & 29.53 & & 1216.1 & 18.778 & & \\
\hline
\end{tabular}

Table 7. GF-PUR bending specimen dimensions and results

\begin{tabular}{|c|c|c|c|c|c|c|c|c|c|c|c|c|}
\hline & & & & & & & & & & & & \\
\hline \# & Face & Core & $\begin{array}{l}\text { Tufting } \\
\text { yarn }\end{array}$ & $\begin{array}{c}\text { Tuft } \\
\text { spacing } \\
(\mathrm{mm})\end{array}$ & $\begin{array}{l}\text { Width } \\
(\mathrm{mm})\end{array}$ & $\begin{array}{l}\text { Length } \\
(\mathrm{mm})\end{array}$ & $\begin{array}{l}\text { Total } \\
\text { Thick } \\
(\mathrm{mm})\end{array}$ & $\begin{array}{l}\text { Span } \\
(\mathrm{mm})\end{array}$ & $\begin{array}{l}\text { Failure } \\
\text { Load } \\
\text { (N) }\end{array}$ & $\begin{array}{c}\text { Facing } \\
\text { bending } \\
\text { stress } \\
\text { (Mpa) }\end{array}$ & $\begin{array}{c}\text { Average } \\
\text { facing } \\
\text { bending } \\
\text { stress } \\
\text { (Mpa) }\end{array}$ & C.V. \% \\
\hline BG1 & & & & - & 91.1 & 350 & 30.9 & & 470.86 & 9.2977 & & \\
\hline BG2 & & & & - & 91 & 349 & 30.8 & & 561.88 & 12.529 & 135 & 20.94 \\
\hline BG3 & GF & PUR & & & 90.6 & 346 & 29.01 & 200 & 1297.9 & 25.442 & & \\
\hline BG4 & & & Aramid & 12.5 & 90.7 & 346 & 29.1 & & 1130.2 & 21.163 & 23.2911 & 9.186 \\
\hline BG5 & & & & & 91.2 & 347 & 29.23 & & 1330.6 & 23.269 & & \\
\hline
\end{tabular}

